\title{
QUEBRA DE DICOTOMIAS NO ENTRE(-)LUGAR ROSIANO
}

\section{Viveca Pontes de Miranda Soares Ramalho}

Resumo: Este trabalho propõe uma leitura do conto "A terceira margem do rio", de João Guimarães Rosa, a partir da análise do protagonista "pai", apontando para a possibilidade de o conto representar uma metáfora do conceito de "terceiro espaço", formulado por Homi K.Bhabha. O conto constitui, portanto, uma forma estética desse terceiro espaço, ocupado pela personagem "pai", figura complexa de diferença e identidade que abre uma possibilidade de um hibridismo cultural, desejo firmado na literatura como uma difícil luta dos povos subordinados de firmar suas tradições culturais nativas e recuperar suas histórias reprimidas.

Palavras-chave: Entre-lugar; cultural; travessia; ultrapassar fronteiras

Uma fronteira não é o ponto onde algo
termina, mas, como os gregos
reconheceram, a fronteira é o ponto a partir
do qual algo começa a se fazer presente.
Martin Heidegger

Desde o título, que afasta a noção de duas margens, "A terceira margem do rio" (1962), de João Guimarães Rosa, representa a concepção do "entre-lugar". Nesse sentido, o protagonista "pai" representa a condição de sujeito híbrido, situado num terceiro espaço, revelando um mundo estranho, a meio caminho e afastado de uma idéia de sociedade em termos binários. A fábula gira em torno do seguinte argumento: Um homem abandona família e sociedade, para viver à deriva numa canoa, no meio de um grande rio. Com o tempo, todos, menos o filho primogênito, desistem de tentar resgatá-lo e abandonam o local. A estranheza representada no texto pelas ações excêntricas da personagem "pai" reflete também a mobilidade do sujeito na contemporaneidade, questionadora do status quo, já que, ironicamente, quem sofre mais mudanças na narrativa é justamente $o$ patriarca e não o filho jovem.

Mestranda em Literatura Brasileira (Ufal). 
Segundo Cirlot ${ }^{1}$,"o rio é símbolo ambivalente, pois se de um lado simboliza a fertilidade, por outro lado, representa o transcurso irreversível" e significa o re-existir num terceiro espaço, no ir- e- vir da vida, entendendo-o como a mobilidade do sujeito no mundo contemporâneo, já que significa busca, travessia, quebra de dicotomias, rumo ao inominável.

$\mathrm{Se}$, aparentemente, o conto apresenta o prosaico - o abandono do lar da figura tradicional do provedor da família, "o movimento da narrativa é enformado por dúvidas, interrogações, suspensões e medo, representado por seus personagens" ${ }^{2(2)}$ especialmente pela personagem "pai", sujeito inominável, mas nuclear da travessia que simboliza o tenso esforço de superação na contemporaneidade de categorias dicotômicas rígidas tradição/mudança -, representando o espaço de uma estranha e incompreendida resistência. Mas o rio constitui também na narrativa o espaço intervalar das idas e vindas das águas inseguras e transitórias da linguagem encantatória do conto. Observa-se que quem vai e vem é a personagem, mas a linguagem, via personagem-narrador, acompanha essa mobilidade na linguagem enunciativa:

Nosso pai não voltou. Ele não tinha ido a nenhuma parte.

Só executava a invenção de se permanecer naqueles espaços do rio, de meio a meio, sempre dentro de uma canoa, para dela não saltar, nunca mais. A estranheza dessa verdade deu para estarrecer de todo a gente ${ }^{3)}$. (TMR, p.33)

E a canoa saiu se indo[...] comprida longa. (TMR, p.33)

De dia e de noite, com sol ou aguaceiros, calor, sereno, e nas friagens terríveis de meio-do-ano [...] sem fazer conta de se-ir do viver. (TMR, p.34)

1 CIRLOT, Juan-Eduardo. Dicionário de símbolos. (Trad. De Rubens Eduardo Ferreira Frias). São Paulo: Moraes, 1984, p.499.

2 COVIZZI, Lenira Marques. O insólito em Guimarães Rosa e Borges. São Paulo:Ática, 1987, p.74.

3 ROSA, João Guimarães. A terceira margem do rio. In: ROSA, Guimarães. Primeiras estórias. Rio de janeiro: Nova Fronteira, 1988. A partir desta marcação, os textos relativos ao conto em análise serão . referenciados, no corpo de trabalho, como TMR = "A terceira margem do rio". 
De que é que eu tinha tanta culpa? Se o meu pai, sempre fazendo ausência: e o rio-rio-rio-, o rio. (TMR, p.36)

$\mathrm{E}$, eu, rio abaixo, rio a fora, rio a dentro - o rio. (TMR, p.37)

Covizzi ${ }^{4}$ nos chama a atenção para "a visão de mundo de Guimarães Rosa e da importância do processo, do movimento, para a apreensão mais global do que se intenta conhecer". Para Rosa o homem não está condenado ao determinado, nem é classificado dentro do que é fixo, feito, finito; mas pode significar probabilidade, virtualidade e, sobretudo, possibilidade. Segundo Antonio Candido, ${ }^{(5) 5}$ o mundo e o homem para Rosa "são abismos de virtualidades, e ele [o autor] será tanto mais original quanto mais fundo baixar na pesquisa, trazendo como resultado um mundo e um homem diferentes, compostos de elementos que deformou a partir de modelos reais, conscientes ou inconscientemente propostos". Em Grande sertão: veredas o jagunço Riobaldo afirma: "porque aprender-a-viver é o que é viver, mesmo," tendo como núcleo o homem pois o que "existe é o homem humano. Travessia."7

Em "A terceira margem do rio", vê-se também representado no ser ficcional o homem desterrado de seu espaço, errante, diaspórico, numa travessia solitária, sem retorno, "nesse rio do meio que tudo carrega" 8 significando o homem moderno, descentrado, deslocado e sem volta a um verdadeiro lar que já não pode existir:

4 COVIZZI, ibidem. p.70.

5 CANDIDO, Antonio. O Homem dos avessos. In: CANDIDO, Antonio

Tese e antítese. São Paulo: Companhia Editora Nacional, 1964; $3^{\mathrm{a}}$ edição, 1978, p.122.

6 ROSA, João Guimarães. Ficção Completa. Rio de Janeiro: Nova Aguilar, 1994, p.371.

7 ROSA, 1994, .p.385

8 LUFT, Lya. O rio do meio. 13. ed. Rio de Janeiro: Record, 2004, p.44. "O rio do meio que tudo carrega" representa para Luft o espaço de negociação das sombras (facetas) que constitui nossa identidade, que segundo a autora está em "permanente duelo: uma convencional, que faz tudo 'direito'; outra, a estranha, agachada no porão da alma ou num sótão penumbroso; que é louca, assustadora, quer rasgar as tábuas da lei, 
Nosso pai passava ao largo, [...] sem fazer conta do se-ir do viver. Não pojava em nenhuma das duas beiras, nem nas ilhas e croas do rio, não pisou mais em chão nem capim (TMR, p.34)

Segundo o crítico Stuart Hall, ${ }^{9}$ com a demarcação de novos espaços na modernidade "o sujeito assume identidades diferentes em momentos diversos, identidades que não estão unificadas em torno de um self coerente".Sua afirmativa está baseada no seguinte argumento:

Um tipo distinto de mudança estrutural está transformando as sociedades modernas no final deste século, fragmentando as paisagens culturais de classe, gênero, sexualidade, etnicidade, raça e nacionalidade que nos deram localizações sólidas como indivíduos sociais. Estas transformações estão também modificando nossas identidades pessoais, enfraquecendo nossa percepção de nós mesmos como sujeitos integrados, esta perda de um sentimento estável do self é algumas vezes chamada de deslocamento ou descentramento do sujeito. ${ }^{10}$

A não nominação das personagens em "A terceira margem do rio" revela de certa forma essa perda estável do self, descrito por Stuart Hall, condição coerente com a modernidade em que as personagens se identificam pela condição que ocupam na sociedade e no núcleo familiar: "pai", "mãe", "irmão", "irmã", "padre". Segundo Walnice Galvão, " o sábio uso do possessivo plural de primeira pessoa - nosso pai, nossa mãe, nossa casa, tio nosso, aparentados nossos - unido à omissão de nomes próprios, ressalta, neste conto, $\mathrm{o}$ peso das relações de família e de geração, aplastando a individualidade. Rosa e Silva explica o descentramento das personagens nas narrativas do final do século $\mathrm{XX}$, afirmando que

transgredir, voar com as bruxas, romper com o cotidiano. E interfere naquela, 'boazinha', que todos pensam conhecer tão bem".

9 HALL, Stuart.Identidade Cultural. São Paulo: Memorial da América Latina, 1997, p.10.

10 Ibidem, p.5.

11 GALVÃ̃, Walnice Nogueira. Mitologia rosiana. Ensaios, 37. São Paulo: Ed. Ática, 1978, p.40. 
A partir das teorias de Freud, não é possível definir o indivíduo como uma globalidade ético-psicológica coerente, expressa por um eu racionalmente configurado: o eu social é uma máscara e uma ficção, sob as quais se agitam forças inominadas e se revelam múltiplos eus, profundos e conflitantes. ${ }^{12}$

O signo do rio, que simboliza mobilidade ou passagem, é uma imagem forte nessa narrativa e sempre exerceu grande fascínio em Guimarães Rosa, pois é o próprio autor que afirma:

Amo os grandes rios, pois são profundos como a alma do homem. Na superfície são muito vivazes e claros, mas nas profundezas são tranqüilos e escuros como os sofrimentos dos homens. Amo ainda mais uma coisa de nossos grandes rios: a eternidade. Sim, rio é uma palavra mágica para conjugar a eternidade. ${ }^{13}$

Benedito Nunes ${ }^{14}$ discute o motivo da viagem na obra de Rosa e afirma que "[...] não há, de um lado, o mundo, e, de outro, o homem que atravessa. Além de viajante, o homem é a viagem, objeto e sujeito da travessia" que simboliza, em minha leitura, o esforço de superação na contemporaneidade de categorias dicotômicas rígidas, sendo o rio o "terceiro espaço" ou "entre-lugar" desse movimento. Guimarães Rosa opta pelo signo de mobilidade - o rio - para representar a mobilidade do sujeito e do mundo contemporâneo e dos papéis identitários na cultura brasileira.

Em Cultura brasileira e culturas brasileiras, ${ }^{15}$ Alfredo Bosi nos convida a refletir a respeito das culturas brasileiras, colocando como fundamentais as idéias de pluralidade e de relacionamento entre essas diferenças culturais, que não se fundem mutuamente, mas

12 DALTON TREVISAN: ficção e consciência do ser. Revista do Programa de Pós-Graduação em Letras: número temático de literatura: o conto. Maceió: Imprensa Universitária, n.19, p.52, jan/jun 1997,

13 Arte em revista, São Paulo, Cenac, ano I, maio/agosto, 1979.

14 NUNES, Benedito. O dorso do tigre. São Paulo: Ática, 1978, p.179.

15 BOSI, Alfredo. Cultura brasileira, culturas brasileiras. In: Dialética da colonização. São Paulo: Companhia das Letras, 1992, p. 308-310. 
mantêm relacionamentos de tensão e troca. Neste sentido, trocas culturais são um dos passos de configuração da mobilidade e descentramento do sujeito. Podemos estender essas reflexões a todas as Américas compostas de países que sofreram processos colonizadores muito semelhantes e nos quais os povos autóctones foram aniquilados ou menosprezados pelo olhar do Outro. Ao discutir nossa compreensão das misturas e mestiçagens, Serge Gruzinski afirma que, se por um lado tais povos sofreram a perda das referências provocada pela era da Conquista, deixando as populações indígenas desorientadas ou prostradas, dado ao enfraquecimento das dinastias indígenas, os estragos das epidemias, a proibição das formas públicas de idolatria e a exploração desenfreada de que são vítimas, por outro lado, tais fatos geram um imbricamento entre esses dois mundos - o do ocidente cristão e o do ameríndio. Nessa perspectiva, misturas e mestiçagens perdem o aspecto de uma desordem passageira e torna-se uma dinâmica fundamental:

Aqui, deixa de valer a metáfora do encadeamento, da sucessão ou da substituição, que serve de base à interpretação evolucionista, pois não apenas o tempo dos vencidos não é automaticamente substituído pelo dos vencedores, como pode coexistir com ele séculos a fio. Ao juntar abruptamente humanidades há muito separadas, a irrupção das misturas abala a representação de uma evolução única do devir histórico e projeta luz nas bifurcações, nos entraves e nos impasses que somos obrigados a levar em conta. ${ }^{16}$

Assim, a realidade imposta pelo Outro não é de todo estéril e opressora, pelo contrário, ela estimula capacidades de invenção e improvisação, exigência da própria sobrevivência num contexto misturado e fragmentado (indo-afro-europeu). A introdução dessa "impureza" salutar, presente desde os primeiros momentos de nossa formação cultural, evidencia a inclinação das escrituras latinoamericanas de se firmarem no "entre-lugar", como tão bem analisa o crítico Silviano Santiago :

16 GRUZINSKI, Serge. O pensamento mestiço. Trad. Rosa Freire d'Aguiar. São Paulo: Companhia das Letras, 2001, p.58. 
A maior contribuição da América Latina para a cultura ocidental vem da destruição sistemática dos conceitos de unidade e de pureza, esses dois conceitos perdem o contorno exato do seu significado, perdem seu peso esmagador, seu sinal de superioridade cultural, à medida que o trabalho de contaminação dos latino-americanos se afirma, se mostra mais e mais eficaz ${ }^{.17}$

Sabemos que a literatura e, por extensão, a ficção possibilita sempre um espaço de crítica da cultura. Dessa forma, "A terceira margem do rio" sugere, em Primeiras estórias (1962), de Guimarães Rosa, uma possibilidade de representação poética da desarticulação da ordem brasileira patriarcal a partir de uma mobilidade romanesca da personagem, sinalizando para uma saída singular, em que o "entrelugar" ou o "terceiro espaço"possa ser entendido como o território da problematização do sujeito, alternativa problematizadora aos binarismos redutores que é um espaço de interpenetrações em que o Outro passa a ser respeitado.Segundo Bhabha, toda a problemática identitária e as exclusões que dela decorrem precisam ser repensadas para além do binarismo redutor inscrito nos termos opositivos: negro versus branco; mulheres versus homens, heterossexuais versus homossexuais. Para ele "a passagem intersticial entre identificações fixas abre a possibilidade de um hibridismo cultural que acolhe a diferença sem uma hierarquia suposta ou imposta," 18 configurando o terceiro espaço ou espaço intersticial que não deve ser confundido, no entanto, com um terceiro termo, mas um in-between (entre-lugar) que os engloba e os ultrapassa:

O que é teoricamente inovador e politicamente crucial é a necessidade de passar além das narrativas de subjetividades originárias e iniciais e de focalizar aqueles momentos ou processos que são produzidos na articulação de diferenças culturais.Esses "entre-lugares" fornecem o terreno para elaboração de estratégias de subjetividade - singular ou

17 SANTIAGO, Silviano. 2. ed. Uma literatura nos trópicos: ensaios sobre dependência cultural. Rio de Janeiro: Rocco, 2000.

18 BHABHA, Homi K. Locais da cultura. In: BHABHA, Homi. O local da cultura. Belo Horizonte: Ed. UFMG, 1988, p.22. 
coletiva - que dão início a novos signos de identidade e postos inovadores de colaboração e contestação, no ato de definir a própria idéia de sociedade. ${ }^{19}$

A ênfase na substituição das narrativas de origem pura pelas novas narrativas, como a de Rosa, que instauram a mobilidade dos papéis e relatos, reflete uma metáfora da "tradução cultural", conceito fundamental para Bhabha discutir, em meio a outros críticos póscolonialistas, a noção da diferença cultural a partir da perspectiva dos diferentes. Rosa surge num contexto em que a teoria de dependência em relação ao original é superada pela possibilidade de recriação e autonomia. O termo "tradução", vem, etimologicamente, do latim, significando "transferir", "transportar entre fronteiras", conceito que descreve aquelas formações de identidades que atravessam e intersectam as fronteiras "naturais" nas sociedades.

No texto de Guimarães Rosa, o patriarca se move de forma inabitual no decurso da narrativa; em "A terceira margem do rio", seu lugar de poder (a casa, a família) é, em primeira instância, anulado por perplexidades.

A estranheza dessa verdade deu para estarrecer de todo a gente. Aquilo que não havia acontecia. Os parentes, vizinhos e conhecidos nossos, se reuniam, tomavam juntamente conselho (TMR, p.33).

Mandou vir o tio nosso, irmão dela, para auxiliar na fazenda e nos negócios. Mandou vir o mestre, para nós, os meninos. Incubiu o padre que um dia se revestisse, em praia de margem, para esconjurar e chamar o nosso pai o dever de desistir da tristonha teima (TMR, p.34).

Em seguida, no entanto, tal modificação instaura uma necessidade (a nosso ver positiva) de os outros se fazerem ouvir: o filho que fala, "Pai, o senhor me leva junto, nessa sua canoa?" (p.33). Nesse sentido, as fronteiras de papéis identitários no conto são mobilizadas.

Analisando textos poéticos ou críticos da diferença, pode-se afirmar que a significação mais ampla da modernidade converge para a compreensão de que as "fronteiras" são ultrapassáveis e que uma

19 BHABHA, op. cit., p.20. 
variedade de outras vozes e histórias dissonantes e dissidentes de mulheres, colonizados, grupos minoritários ou portadores de sexualidade policiada são possíveis de serem escutadas, enformando assim a "paisagem cultural" de que Stuart Hall trata.

Os conceitos de culturas nacionais homogêneas e a transmissão de tradições históricas encontram-se em profundo processo de redefinição e cada vez mais as "culturas nacionais" estão sendo traduzidas a partir da perspectiva de minorias destituídas. É o caso de autores como a afro-americana Toni Morrison e o indiano Salmon Rushdie, apenas para citar alguns, que reescrevem suas histórias, que são histórias de um povo sob o olhar fiel do sujeito cindido (o imigrante). Edward Said ${ }^{20}$ afirma que "a moderna cultura ocidental é, em larga medida, obra de exilados, emigrantes, refugiados. Nos Estados Unidos, o pensamento acadêmico, intelectual e estético é o que é hoje graças aos refugiados da fascismo, do comunismo e de outros regimes dados a oprimir e expulsar os dissidentes". Bhabha - ele próprio um teórico que assume uma condição desfavorável pois é estrangeiro do "terceiro mundo", traduzindo criticamente, e a partir de um lugar crítico também híbrido, um intelectual do terceiro mundo no Reino Unido, os cânones rígidos do "primeiro mundo" - afirma que:

O além não é um novo horizonte, nem um abandono do passado[...] inícios e fins podem ser os mitos de sustentação dos anos no meio do século, mas neste finde-siècle, encontramo-nos num momento de trânsito em que espaço e tempo se cruzam para produzir figuras complexas de diferença e identidade, passado e presente, interior e exterior, inclusão e exclusão. Isso porque há uma sensação de desorientação, um distúrbio de direção, no "além"; um movimento exploratório incessante, que o termo francês au-delà capta tão bem - aqui e lá, de todos os lados, for/da, para lá e pra cá, para frente e para trás. ${ }^{21}$

20 SAID, Edward. W. Reflexões sobre o exílio e outros ensaios; tradução Pedro Maia Soares - São Paulo: Companhia das Letras, 2003.

21 BHABHA, Homi K. Locais da cultura. In: BHABHA, Homi. O local da cultura. Belo Horizonte: UFMG, p.19 
E é exatamente a partir desse lugar de enunciação dos diferentes que se constrói o momento de trânsito ou travessia que vemos, em "A terceira margem do rio" um personagem que, de forma súbita e estranha, abandona família e vida social - instituições que subsidiaram tematicamente as narrativas sociais dos séculos XIX e início do XX para viver à deriva, em uma canoa "de pau de vinhático, pequena, mal com a tabuinha da popa, como para caber justo o remador" (TMR,p.32), possibilitando a discussão na contemporaneidade da questão da mobilidade e questionamento do conceito de fronteiras e certezas dicotômicas.

Nossa mãe, a gente achou que ela ia esbravejar, mas persistiu alva de pálida, mascou o beiço e bramou: "Ce vai, ocê fique, você nunca volte!" Nosso pai suspendeu a resposta.(TMR, p.32).

O silêncio do "pai" diante do sofrimento da esposa abandonada, instaura no texto uma face singular da condição humana, suas impossibilidades e necessidades, cujo estatuto é o de ser incompleto que só existe plenamente enquanto busca e desejo, reflexo de um eterno vir-a-ser. Mas o que nos chama a atenção nesse conto é o fato de que quem sofre a maior mudança é o patriarca, imagem de força e estabilidade nas narrativas da tradição e não o jovem (filho), o que sugere uma solução narrativa estranha, questionadora do status quo, dado a atitude do pai "de se permanecer naqueles espaços do rio, de meio a meio, sempre dentro de uma canoa, para dela não saltar, nunca mais"' (TMR, p.33).

Depois de várias tentativas frustradas, a família desiste de apelar para o retorno do pai e abandona o local, com exceção do filho primogênito que, convencido de que o pai precisava dele, se torna cúmplice do inusitado projeto:

Eu nunca podia querer me casar. Eu permaneci, com as bagagens da vida. Nosso pai carecia de mim, eu sei - na vagação, no rio no ermo - sem dar razão de seu feito (TMR, p.35-36).

Permanece, então, no local e já de cabelos brancos e "de tristes palavras" (p.36), decide substituí-lo na canoa, 
Pai, o senhor está velho, já fez o seu tanto... Agora, o senhor vem, não carece mais... o senhor vem, e eu, agora mesmo, quando que seja, a ambas vontades, eu tomo o seu lugar, do senhor, na canoa!...(TMR, p.36)

mas apavora-se e foge ao vislumbrar a possibilidade da troca em vida:

Sou o que não foi, o que vai ficar calado. Sei que agora é tarde, e temo abreviar com a vida, nos rasos do mundo. Mas, então, ao menos que, no artigo da morte, peguem em mim, e me depositem também numa canoinha de nada, nessa água que não pára, de longas beiras: e, eu, rio abaixo, rio a fora, rio a dentro - o rio. (TMR, p.37).

No entanto, apesar do sentimento de culpa e da perplexidade familiar diante da inusitada ação paterna, o filho primogênito incorpora o papel do pai, ratificando a idéia de passagem - travessia e de terceira margem: a da mobilidade entre fronteiras sempre ultrapassáveis, aí representados pelos lugares paterno e filial, subitamente confundidos. Observa-se que a última palavra do conto é "rio", eixo líquido, deslizante e contínuo. O texto, portanto, finaliza com a imagem de movimento; ao incorporar o papel do pai, observase que a ordem patriarcal já fora rompida pelo próprio pai que, de provedor do núcleo familiar, passa a ser provido. A família nuclear é, também, fragmentada; paradoxal e conservadoramente o filho incorpora a imagem rebelde de um pai transgressor. Confundem-se os papéis identitários, configura-se a mobilidade do espaço intervalar.

\section{Referências}

BHABHA, HOMI K. Locais da cultura. In: Bhabha, Homi. O local da cultura. Belo Horizonte: Ed. UFMG, 1988.

BOSI, Alfredo. Cultura brasileira, culturas brasileiras. In: Dialética da colonização. São Paulo: Companhia das Letras, 1992.

CANDIDO, Antonio. O homem dos avessos. In: CANDIDO, Antonio.Tese $e$ antítese. São Paulo: Companhia Editora Nacional, 1964; 3. ed., 1978.

COVIZZI, Lenira Marques. O insólito em Guimarães Rosa e Borges. São Paulo: Ática, 1978. 
GALVÃO, Walnice Nogueira. Mitologia rosiana. Ensaios, 37. São Paulo: Ática, 1978.

HALL, Stuart. Identidade cultural. São Paulo: Memorial da América Latina, 1997.

LARAIA, Roque de Barros. Cultura: um conceito antropológico. 14. ed. - Rio de Janeiro: Jorge Zahar, 2001.

NUNES, Benedido. O dorso do tigre. São Paulo: Ática, 1978.

ROSA, João Guimarães. A terceira margem do rio. In: ROSA, Guimarães. Primeiras estórias. Rio de Janeiro: Nova Fronteira, 1988.

ROSA, João Guimarães. Fiç̧ão completa. - Rio de Janeiro: Nova Aguilar, 1994.

RUZINSKI, Serge. $O$ pensamento mestiço; Tradução de Rosa Freire d'Aguiar - São Paulo: Companhia das Letras, 2001.

SAID, Edward W. Reflexões sobre o exílio e outros ensaios; tradução Pedro Maia Soares. São Paulo: Companhia das Letras, 2003.

SANTIAGO, Silviano. Uma literatura nos trópicos: ensaios sobre dependência cultural. 2. ed. - Rio de Janeiro:Rocco, 2000. 